\title{
Substituent Chemical Shifts of 2-Aryl Derivatives of Benzimidazole, Benzimidazolium Ion, and Benzimidazoline
}

\author{
Chang Kiu Lee ${ }^{\star}$ and In-Sook Han Lee ${ }^{\dagger}$ \\ Department of Chemistry, Kangwon National University, Chuncheon 200-701, Korea. "E-mail: cklee410@kanguon.ac.kr \\ ${ }^{\dagger}$ Department of Science Education, Kanguon National University: Chancheon 200-701, Korea \\ Received August 16, 2008
}

\begin{abstract}
NMR spectra of a series of 2-arylbenzinidazoles, 2-aryl-1,3-dimethylbenzimidazoliun iodides, and 2-aryl1,3-dimethylbenzimidazolines were examined by correlating ${ }^{1} \mathrm{H}$ and ${ }^{13} \mathrm{C}$ chemical shift values with the Hammett substituent constants $\sigma$. The signals corresponding to $\mathrm{C}-2$ of the inidazole ring show good correlation with the largest $\rho$ values in each series. The $\rho$ values for $\mathrm{C}-2$ of the benzimidazoles and the benzinidazolium ions were very close, but that of the benzimidazoline was about a half of the fomer series.
\end{abstract}

Key Words : Substituent chemical shifts, Hammett correlation, Benzimidazole derivatives

\section{Introduction}

2-Aryl-1,3-dimethylbenzimidazolium ions (2) and 2-aryl1,3-dimethylbenzimidazolines (3) have been employed as analogues of $\mathrm{NAD}^{-}$and $\mathrm{NADH}$, respectively, for investigation of the mechanism of hydride transfer that takes place in numerous biological processes. ${ }^{1}$ Unlike $\mathrm{NAD}^{-}$and $\mathrm{NADH}$ that have no significant steric effect the 2-aryl substituent in benzimidazole may cause significant stereoelectronic effect on the hydride transfer. However, the unfavorable steric effect on the hydride transfer between the analogues may be partially compensated by the $m$ - and $p$-substituent on the 2phenyl ring, depending on the nature of the substituent.

During the course of our investigation on the rate of hydride transfer, we were interested in the effect of the substituents of the 2-aryl group on the chemical shifts of the ${ }^{1} \mathrm{H}$ and ${ }^{1:} \mathrm{C}$ of the benzimidazole ring. ${ }^{2}$ It can be expected that the electronic nature of the 2-aryl group may affect the reactivity at $\mathrm{C}-2$ to or from which the hydride transfer takes place. Here we report the interesting correlation of the chemical shifts of ${ }^{1} \mathrm{H}$ and ${ }^{15} \mathrm{C}$ of 1,2 , and 3 of the benzimidazole ring with the Hammett substituent parameter $\sigma$.

\section{Results and Discussion}

2-Arylbenzimidazoles (1), 2-aryl-1,3-dimethylbenzimidazolium ions (2), and 2-aryl-1,3-dimethylbenzimidazolines (3) were prepared by following the method of Craig et al. with a slight modification. ${ }^{3}$ The syntheses are summarized in Scheme 1 .
Purification of the products was done mostly by repeated recrystallization from ethanol-water to obtain materials of analytical purity, which are essential for meaningful correlation of the chemical shifts and $\sigma$.

The solutions of the benzimidazole derivatives $\mathbf{1 - 3}$ for NMR analysis were prepared by dissolving them in DMSO$d_{6}$ to $0.1 \mathrm{M}$ concentration. The accurate assignments of the chemical shifts were made with aid of ${ }^{1} \mathrm{H}-{ }^{1} \mathrm{H}$ COSY and ${ }^{1} \mathrm{H}$ ${ }^{13} \mathrm{C}$ HETCOR spectroscopy. The assignments are listed in Tables 2-5. The compounds 1-3 have been reported, and therefore, only the relevant values are listed for the correlation with $\sigma$.

As expected, the benzimidazoles (1) show seven ${ }^{13} \mathrm{C}$ signals for the carbons that compose the ring and the five ${ }^{1} \mathrm{H}$ signals for the protons including the $\mathrm{X}-\mathrm{H} .{ }^{+}$This is because of the prohibited tautomerism of the proton from $\mathrm{N}-1$ to $\mathrm{N}-3$. On the other hand, the benzimidazole skeletons in $\mathbf{2}$ and 3 are symmetric and only the tive ${ }^{13} \mathrm{C}$ signals including the ${ }^{13} \mathrm{CH}_{3}$ are observed, as expected.

It is interesting to notice that the calculated values of the chemical shifts for the carbon atoms of the benzene ring of 2-phenylbenzimidazole (1) and the observed values are fairly close if 1 is considered a disubstituted benzene and the substituents are $-\mathrm{N}=\mathrm{CH}-\mathrm{C}_{6} \mathrm{H}_{5}$ and $-\mathrm{NHCH}_{3}{ }^{5}$ For example, the calculated value for $\mathrm{C}-3 \mathrm{a}$ is $137.0 \mathrm{ppm}$ [base $128.5+$ ipso- $\left.\mathrm{N}=\mathrm{CH}-\mathrm{C}_{6} \mathrm{H}_{5} 24.7+o r t h o-\mathrm{NHCH}_{3}(-16.2)\right]$ and the observed value is 135.74 ppm. Similarly, the calculated (observed) values are: $\mathrm{C}-4 \quad 122.9 \quad(122.25) ; \quad C-5 \quad 118.2$ $(119.41) ; C-6127.8(123.10) ; C-7113.6(111.92)$, and $C-7 \mathrm{a}$ $137.0(144.28)$.

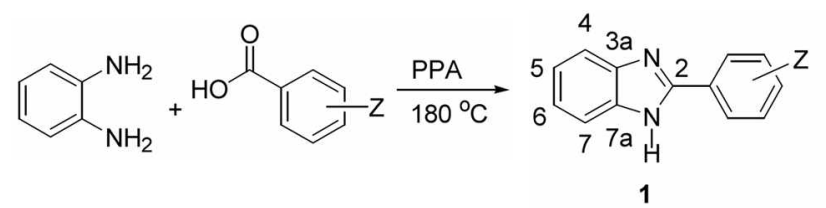

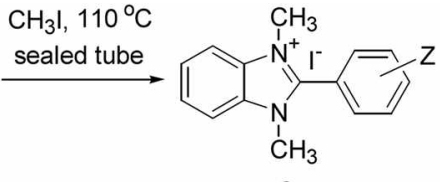

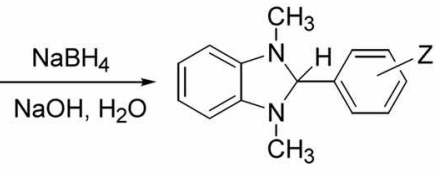

3

Z: a, m-F; b, m-Cl; c, m-Br; d, m-CHis e. p-F; f, p-Cl: g. $\rho-\mathrm{Br} ; \mathbf{h}, p-\mathrm{CH}_{3} ; \boldsymbol{i}, \mathrm{H}$ 
Table 1. Best Fit of the Sungle Substituent Parameter Equation for ${ }^{1} \mathrm{H}$ and ${ }^{13} \mathrm{C}$ Chemical Shifts of $1-3$ in Dimethyl Sulfoxide- $d_{6} t 0.1$ M) in $\mathrm{Hz}$

\begin{tabular}{|c|c|c|c|c|c|c|}
\hline & \multicolumn{2}{|c|}{1} & \multicolumn{2}{|c|}{2} & \multicolumn{2}{|c|}{3} \\
\hline & $\rho$ & r & $\rho$ & $r$ & $\rho$ & $\mathbf{r}$ \\
\hline $\mathrm{CH}_{3}$ & - & - & 46.9 & 0.814 & 23.1 & 0.931 \\
\hline $\mathrm{N}-\mathrm{H}$ & 105.2 & 0.895 & - & - & - & - \\
\hline $2-\mathrm{H}$ & - & - & & & 81.5 & 0.975 \\
\hline $4-\mathrm{H}$ & 110.6 & 0.917 & 63.3 & 0.876 & 15.4 & 0.835 \\
\hline $5-\mathrm{H}$ & 13.2 & 0.610 & 64.7 & 0.858 & 23.1 & 0.916 \\
\hline $6-\mathrm{H}$ & 30.2 & 0.853 & 64.7 & 0.858 & 23.1 & 0.916 \\
\hline $7-\mathrm{H}$ & -86.7 & 0.813 & 63.3 & 0.876 & 15.4 & 0.835 \\
\hline${ }^{1} \mathrm{CH}_{3}$ & - & - & -19.5 & 0.584 & 23.5 & 0.796 \\
\hline $2-C$ & -361.7 & 0.975 & -340.4 & 0.988 & -172.5 & 0.902 \\
\hline $3 a-c$ & -13.0 & 0.324 & -3.3 & 0.279 & -39.8 & 0.985 \\
\hline 4-C & 63.5 & 0.983 & 11.4 & 0.834 & 40.9 & 0.989 \\
\hline $5-C$ & 59.9 & 0.949 & 41.6 & 0.957 & 43.7 & 0.994 \\
\hline $6-C$ & 107.9 & 0.970 & 41.6 & 0.957 & 43.7 & 0.994 \\
\hline $7-\mathrm{C}$ & 47.9 & 0.941 & 11.4 & 0.834 & 40.9 & 0.989 \\
\hline $7 \mathrm{a}-\mathrm{c}$ & -36.8 & 0.896 & -3.3 & 0.279 & -39.8 & 0.985 \\
\hline
\end{tabular}

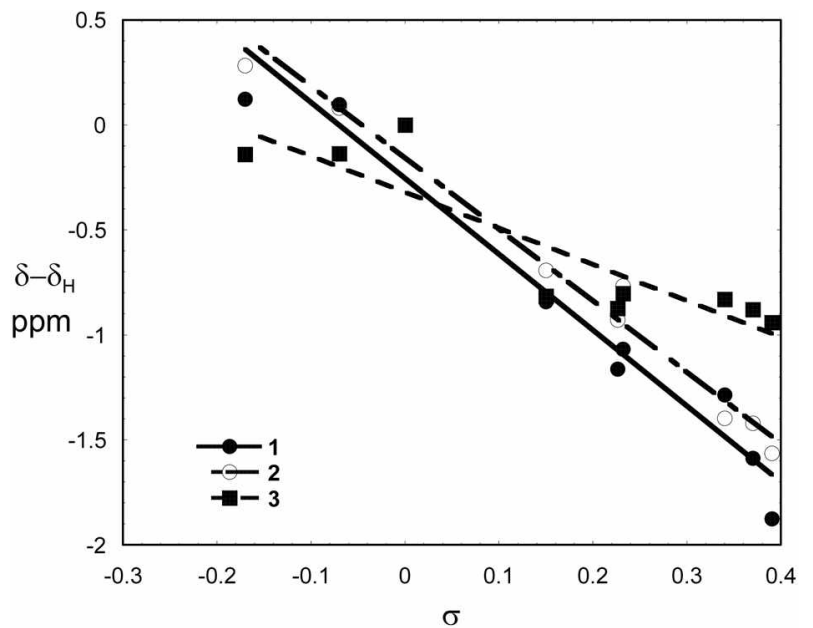

Figure 1. Correlation between $\sigma$ and ${ }^{13} \mathrm{C}$ chemical shifts of $\mathrm{C}-2$ in $1-3$ in DMSO-d.
The substituent effects on the chemical shifts are typically analyzed by the single substituent parameter (SSP) and dual substituent parameter (DSP) approach, which are represented by Equations 1 and 2, respectively. ${ }^{6}$

$$
\begin{gathered}
\delta=\rho \sigma+\delta o \\
\delta=\rho_{\mathrm{l}} \sigma_{\mathrm{l}}+\rho_{\mathrm{R}} \sigma_{\mathrm{R}}+\delta 0
\end{gathered}
$$

Although DSP analysis may be more meaningfil than SSP analysis because it shows both inductive and resonance contribution independently, we have found that SSP analysis is suitable for the purposes of our examination. The results of substituent correlation are listed in Table 1.

One of the striking phenomena is the reverse correlation of the C-2 signals of 1-3 with $\sigma$ as shown in Figure 1. It should also be noted that the magnitudes of the slopes $(\rho)$ are close for $1(-361.7 \mathrm{~Hz})$ and $2(-340.4 \mathrm{~Hz})$, which is approximately twice of that for $3(-172.5 \mathrm{~Hz})$. It is conceivable that the C-2 of 3 is $s p^{3}$-hybridized and the electronic effect of the phenyl ring is not as effectively transmitted as in $\mathbf{1}$ or $\mathbf{2}$ in which the C-2 is $s p^{2}$-hybridized. The negative correlation of the chemical shift with $\sigma$ was reported, just to mention a few examples, for the ipso-Cs of p-substituted biphenyls, the $\alpha$ $C$ s of $p$-substituted styrenes, ${ }^{8}$ and the $\alpha$-Cs of $m$ - and $p$ substituted cinnamoyl fluorides. ${ }^{y}$ However, it seems unusual that the magnitudes of the slopes are close for the carbons in the neutral (1) and the charged (2) imidazole rings. In addition, the average chemical shift values of the 2-C in 1 and in 2 are very close: $150.89( \pm 1.03) \mathrm{ppm}$ for 1 and 150.05 $( \pm 1.00) \mathrm{ppm}$ for 2 , which seem to be unusual for the same reason.

The observation may be useful in understanding the nature of the chemical shift. In general, the chemical shift is believed to be affected most by the local diamagnetic shielding of $p$ electrons around the nucleus, paramagnetic shielding, and neighbor anisotropy effect. ${ }^{10}$ The fact that the chemical shift values for $\mathrm{C}-2$ of 1 and 2 are very close and that the magnitudes of the $\rho$ values are close may be an indication of the significant contribution of the 2-phenyl ring through the resonance structures I-III for $\mathbf{1}$ and IV-VI for $\mathbf{2}$.

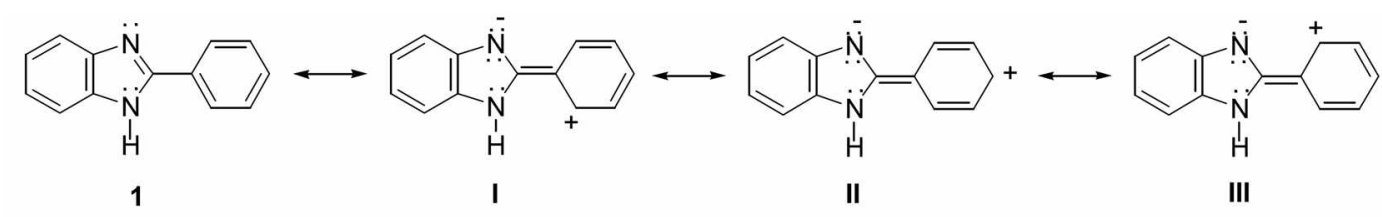

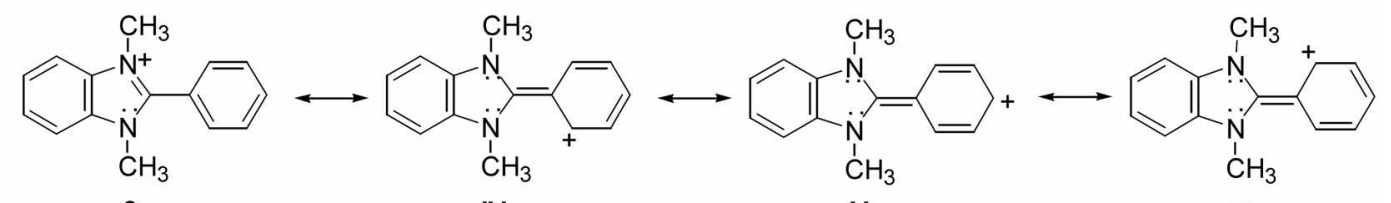

2

IV

V

VI

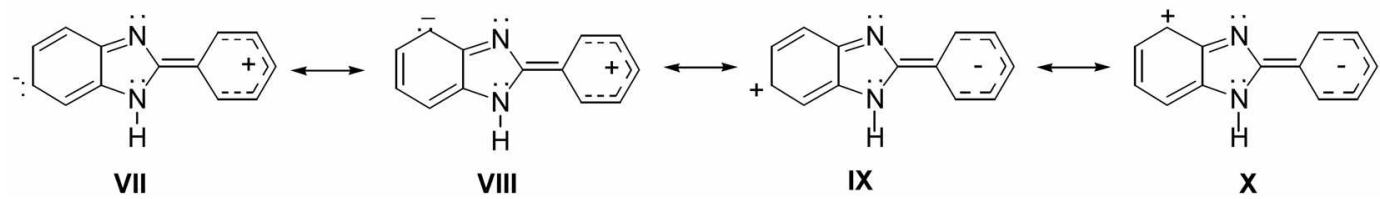


Reverse correlation is also observed for $\mathrm{C}-3 \mathrm{a}(7 \mathrm{a})$ of $\mathbf{3}$. However, the magnitude of slope is close to those for $\mathrm{C}-4(7)$ and $\mathrm{C}-5(6)$ that show normal correlation.

As shown in Table 1, the correlations of ${ }^{13} \mathrm{C}$ with $\sigma$ are better having $r$ values in the range of $0.90-0.99$ than those of ${ }^{1} \mathrm{H}$ with $\sigma$ that show $r$ values ranging $0.81-0.92$, with a few exceptions. One of the striking exceptions is that C-3a of 1 and 2 show absolutely no correlation with $r$ values of 0.324 and 0.279 , respectively. In contrast. C-7a of 1 show a fair correlation $(r=0.896)$ with a negative slope $(\rho=-38.6 \mathrm{~Hz})$. $\mathrm{C}-3 \mathrm{a}$ and $\mathrm{C}-7 \mathrm{a}$ in 1 are different in that the former is bonded to an $s p^{2}$-hybridized $\mathrm{X}$ atom while the latter is bonded to an $s p^{3}$-hybridized ${ }^{\prime}$ atom. The lone pair electrons on $\mathrm{N}-1$ may be positioned to form a hydrogen bond between $\mathrm{X}-1$ and ortho-H of 2-phenyl ring. The electronic effect of the substituent on the phenyl group may also be transmitted to the benzimidazole ring through the hydrogen bridge in addition to ipso-C-C-2 bond. In this way the effect is more effectively and linearly transmitted. This may be the reason that $\mathrm{C}-7 \mathrm{a}$ shows a good correlation.

A similar kind of positioning for the lone pair electrons on $\mathrm{X}-3$ to form $\mathrm{X}-3-$ ortho-H hydrogen bond is not likely. Therefore, the substituent effect on C-3a may be transmitted through $\mathrm{C}-2-\mathrm{N}-3-\mathrm{C}-3 \mathrm{a}$, which is in good contrast to the transmission through ortho-H-N-1-C-7a. The chemical shift of the starred atoms along the latter bonds in 1 show a reverse correlation. Because the starred $\mathrm{C}$-7a shows reverse correlation, $\mathrm{C}$-3a which is adjacent to $\mathrm{C}-7 \mathrm{a}$ is expected to show a normal correlation, as marked $\delta$. However, C-3a can be considered to be an alternating atom which is the part of $\mathrm{C}-2-\mathrm{N}-3-\mathrm{C}-3 \mathrm{a}$ bonds. Because $\mathrm{C}-2$ shows a reverse correlation $\mathrm{C}-3 \mathrm{a}$ is also expected to show a reverse correlation, as marked $\delta^{-}$. As a result of the two conflicting effects, the chemical shift values of $\mathrm{C}-3$ a may show no correlation $(\rho=$ $-13.0 \mathrm{~Hz}, r=0.324)$.
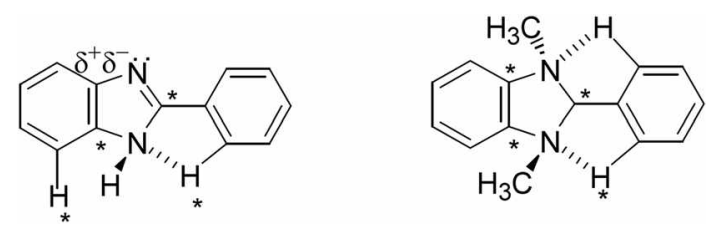

A similar kind of hydrogen bonding is not likely with 2 because the two nitrogen atoms should share the positive charge. On the other hand, the magnetic environment at C$3 a(7 a)$ should be affected most the positively charged $\mathrm{N}$ atom. This may be the reason that the chemical shift of C$3 a(7 a)$ is not linearly correlated with $\sigma(\rho=-3.3, r=0.278)$. In the case of 3 , the electronic effect of the 2-aryl substituent may be transmitted to $\mathrm{C}-3 \mathrm{a}$ (7a) through both ipso-C-C-2 and ortho-H-N-1(3) bonds. Because $\mathrm{C}-3 \mathrm{a}(7 \mathrm{a})$ is a starred atom, it should show a reverse correlation. Indeed, the $\rho$ value is $-39.8 \mathrm{~Hz}$ with a good correlation coefficient $(r=0.985)$.

Then a question may be raised: why do C-4, C-5, C-6, and C-7 of 1-3 show a normal correlation? The electronic effect that is transmitted through bonds should be weaker as the distance from the substituent increases. This is the reason that the $\rho$ values of $\mathrm{C}-2$ is the largest among the values listed in the Table 1. The carbon atoms such as $\mathrm{C}-4 \sim \mathrm{C}-7$ are far apart from the 2-aryl group. So their chemical shifts may not be significantly influenced by the electronic effect of the aryl substituent that is transmitted through bonds. On the other hand, they are likely to be affected by the electronic effect transmitted through space. Through-space transmission is most effective at the end of the dipole. This may be the reason that $C-5$ and $C-6$ show larger $\rho$ values than do $C-4$ and $\mathrm{C}-7$. The magnitude of the through-space transmission may be close among 1,2 , and 3 . But the effect of conjugation is still present in $\mathbf{1}$, and either a positive or negative charge is like to be present at $\mathrm{C}-4$ and $\mathrm{C}-6$ as shown in VII$X$. The second largest $\rho$ value $(107.9 \mathrm{~Hz})$ for $\mathrm{C}-6$ of 1 may be consistent with such a rationale.

Unlike ${ }^{13} \mathrm{C}$ chemical shifts, the ${ }^{1} \mathrm{H}$ chemical shifts show inconsistent correlation with $\sigma$. All of them show normal trends except $\mathrm{H}-7$ of 1 . Although we cannot provide a proper explanation for the exception, the electronic effect transmitted through bonds seems to be predominant over the throughspace transmission and the starred-unstarred alternating phenomena seems to appear in this case.

In conclusion, the substituent chemical shift correlations examined with the benzimidazoles, benzimidazolium ions, and benzimidazolines show that the electronic effect of the substituent in the phenyl ring is transmitted with approximately the same magnitude to an $s p^{2}$-hybridized carbon atom regardless of the presence of a positive charge. The magnitude of the electronic effect transmitted to an $s p^{3}$ hybridized carbon atom is approximately half of that to an $s p^{2}$-hybridized carbon atom.

\section{Experimental}

Nuclear magnetic resonance (NMR) spectra were recorded on a Bruker DPX-400 FT XMR spectroneter in the Central Lab of Kangwon National University at $400 \mathrm{MHz}$ for ${ }^{1} \mathrm{H}$ and $100 \mathrm{MHz}$ for ${ }^{13} \mathrm{C}$ and were referenced to tetramethylsilane. The concentration of the solution was $0.10 \mathrm{M}$ in DMSO- $d_{6}$. Each solution was prepared in a $1 \mathrm{~mL}$ cylindrical volumetrical flask by weighing the compound into the flask and filling with solvent containing 1\%-TMS. A portion $(0.6 \mathrm{~mL})$ of the solution was transferred into an NMR tube

Table 2. 'H NMR Chemical Shift Values $(\mathrm{Hz})$ of Benzimidazoles (1) in DMSO-do

\begin{tabular}{lcccccc}
\hline & $\sigma$ & $\mathrm{NH}$ & $4-\mathrm{H}$ & $5-\mathrm{H}$ & $6-\mathrm{H}$ & $7-\mathrm{H}$ \\
\hline $1 \mathbf{a}$ & 0.34 & 5225.39 & 3076.05 & 2893.51 & 2893.51 & 3041.86 \\
$1 \mathbf{b}$ & 0.37 & 5215.62 & 3074.045 & 2883.29 & 2900.45 & 3016.93 \\
$1 \mathfrak{c}$ & 0.39 & 5216.04 & 3075.73 & 2882.76 & 2899.81 & 3019.63 \\
$\mathbf{1 d}^{\omega}$ & -0.07 & 5176.08 & 3020.78 & 2880.60 & 2885.40 & 3072.02 \\
$1 \mathbf{e}$ & 0.15 & 5189.33 & 3069.72 & 2880.67 & 2885.36 & 3022.56 \\
$\mathbf{1 f}$ & 0.226 & 5199.08 & 3069.08 & 2878.78 & 2894.73 & 3016.105 \\
$1 \mathbf{g}$ & 0.232 & 5211.27 & 3067.98 & 2885.02 & 2889.11 & 3021.95 \\
$1 \mathbf{h}^{b}$ & -0.17 & 5149.25 & 3012.19 & 2874.88 & 2879.57 & 3060.12 \\
$1 \mathbf{i}$ & 0.00 & 5202.28 & 3055.20 & 2884.20 & 2893.16 & 3055.62 \\
\hline
\end{tabular}

'3'-CH3: $958.85 \mathrm{~Hz}(\delta 2.40) . ~ " 4 '-\mathrm{CH}_{3}: 945.80 \mathrm{~Hz}(\delta 2.36)$. 
Table 3. 'S NMR Chemical Shift Values (ppm) of Benzimidazoles (1) in DMSO-d6

\begin{tabular}{lcccccccc}
\hline & $\sigma$ & $2-\mathrm{C}$ & $3 \mathrm{a}-\mathrm{C}$ & $4-\mathrm{C}$ & $5-\mathrm{C}$ & $6-\mathrm{C}$ & $7-\mathrm{C}$ & $7 \mathrm{a}-\mathrm{C}$ \\
\hline $\mathbf{1 a}$ & 0.34 & 150.54 & 135.50 & 122.50 & 119.64 & 123.48 & 112.07 & 144.20 \\
$\mathbf{1 b}$ & 0.37 & 150.23 & 135.50 & 122.48 & 119.60 & 123.50 & 112.04 & 144.15 \\
$\mathbf{1 c}$ & 0.39 & 149.95 & 135.50 & 122.47 & 119.60 & 123.49 & 112.04 & 144.15 \\
$\mathbf{1 \mathbf { d } ^ { \pi }}$ & -0.07 & 151.92 & 135.54 & 122.19 & 119.37 & 123.02 & 111.85 & 144.36 \\
$\mathbf{1 e}$ & 0.15 & 150.98 & 135.61 & 122.29 & 119.40 & 123.09 & 111.90 & 144.34 \\
$\mathbf{1 f}$ & 0.226 & 150.66 & 135.52 & 122.36 & 119.47 & 123.30 & 111.93 & 144.23 \\
$\mathbf{1 g}$ & 0.232 & 150.75 & 135.55 & 122.40 & 119.50 & 123.32 & 111.98 & 144.26 \\
$\mathbf{1 h}$ & -0.17 & 151.94 & 135.49 & 122.14 & 119.25 & 122.90 & 111.75 & 144.35 \\
$\mathbf{1 i}$ & 0.00 & 151.82 & 135.74 & 122.25 & 119.41 & 123.10 & 111.92 & 144.28 \\
\hline
\end{tabular}

'3'-CH: $21.59 \mathrm{ppm} .{ }^{\prime \prime} 4 '-\mathrm{CH}: 21.52 \mathrm{ppm}$.

Table 4. ${ }^{\mathrm{H}} \mathrm{H}$ NRR Chemical Shift Values (Hz) and ${ }^{13} \mathrm{C}$ NMR Chemical Shift Values (ppm) of Benzimidazolium Ions (2) in DMSO- $d_{6}$

\begin{tabular}{lcccccccc}
\hline & $\mathbf{C} \underline{\mathrm{H}}:$ & $4 / 7-\mathrm{H}$ & $5 / 6-\mathrm{H}$ & $\underline{\mathrm{C}} \mathrm{H}_{3}$ & $2-\mathrm{C}$ & $3 \mathrm{a} / 7 \mathrm{a}-\mathrm{C}$ & $4 / 7-\mathrm{C}$ & $5 / 6-\mathrm{C}$ \\
\hline $\mathbf{2 a}$ & 1564.31 & 3265.60 & 3113.07 & 33.31 & 149.37 & 132.18 & 114.01 & 127.32 \\
$\mathbf{2 b}$ & 1569.22 & 3270.95 & 3122.40 & 33.33 & 149.35 & 132.20 & 113.99 & 127.34 \\
$\mathbf{2 c}$ & 1569.85 & 3270.57 & 3119.57 & 33.39 & 149.20 & 132.17 & 113.98 & 127.30 \\
$\mathbf{2 d ^ { \pi }}$ & 1558.97 & 3247.40 & 3096.58 & 33.50 & 150.85 & 132.18 & 113.94 & 127.11 \\
$\mathbf{2 e}$ & 1555.76 & 3256.81 & 3102.63 & 33.45 & 150.07 & 132.20 & 113.97 & 127.19 \\
$\mathbf{2 f}$ & 1564.15 & 3264.35 & 3108.98 & 33.47 & 149.84 & 132.23 & 113.99 & 127.21 \\
$\mathbf{2 g}$ & 1557.65 & 3253.77 & 3105.74 & 33.38 & 150.00 & 132.23 & 113.95 & 127.24 \\
$\mathbf{2 h}$ & 1556.20 & 3251.77 & 3100.95 & 33.39 & 151.05 & 132.23 & 113.93 & 127.11 \\
$\mathbf{2 i}$ & 1556.42 & 3252.13 & 3098.88 & 33.48 & 150.76 & 132.19 & 113.95 & 127.14 \\
\hline
\end{tabular}

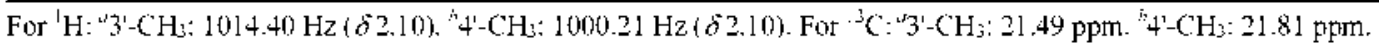

Table 5. 'H NMR Chemical Shift Values ( $\mathrm{Hz}$ ) and ${ }^{13} \mathrm{C}$ NMR Chemical Shift Values (ppm) of Benzimidazolines (3) in DMSO- $d 6$

\begin{tabular}{lccccccccc}
\hline & $\mathrm{C} \underline{\mathrm{H}}$ & $2-\mathrm{H}$ & $4 / 7-\mathrm{H}$ & $5 / 6-\mathrm{H}$ & $\underline{\mathrm{C}} \mathrm{H}_{3}$ & $2-\mathrm{C}$ & $3 \mathrm{a} / 7 \mathrm{a}-\mathrm{C}$ & $4 / 7-\mathrm{C}$ & $5 / 6-\mathrm{C}$ \\
\hline $\mathbf{2 a}$ & 901.74 & 1870.67 & 2555.99 & 2492.54 & 33.67 & 92.89 & 142.29 & 106.44 & 119.72 \\
$\mathbf{2 b}$ & 897.95 & 1869.01 & 2555.58 & 2491.34 & 33.67 & 92.84 & 142.27 & 106.45 & 119.74 \\
$\mathbf{2 c}$ & 902.90 & 1871.84 & 2560.17 & 2496.12 & 33.68 & 92.78 & 142.25 & 106.44 & 119.73 \\
$\mathbf{2 d}^{a}$ & 889.84 & 1829.62 & 2550.36 & 2482.27 & 33.62 & 93.58 & 142.46 & 106.27 & 119.54 \\
$\mathbf{2 e}$ & 895.24 & 1860.02 & 2558.14 & 2492.41 & 33.55 & 92.90 & 142.35 & 106.37 & 119.64 \\
$\mathbf{2 f}$ & 895.74 & 1862.31 & 2557.91 & 2492.85 & 33.58 & 92.84 & 142.31 & 106.40 & 119.67 \\
$\mathbf{2 g}$ & 896.22 & 1858.55 & 2557.76 & 2493.36 & 33.60 & 92.91 & 142.32 & 106.41 & 119.68 \\
$\mathbf{2} \mathbf{h}^{b}$ & 887.16 & 1828.02 & 2550.52 & 2482.22 & 33.51 & 93.57 & 142.46 & 106.24 & 119.50 \\
$\mathbf{2 i}$ & 894.90 & 1845.50 & 2550.95 & 2484.14 & 33.57 & 93.72 & 142.43 & 106.28 & 119.55 \\
\hline
\end{tabular}

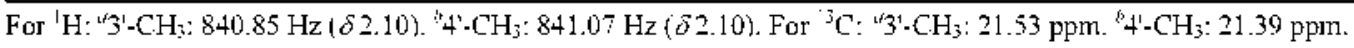

and the spectrum was obtained at $20^{\circ} \mathrm{C}$. The chemical shift values are listed in Tables 2-5 only for the protons (in $\mathrm{Hz}$ ) and carbons (in ppm) of the benzimidazole rings because the benzimidazoles 1,2 , and $\mathbf{3}$ are all known compounds. ${ }^{1]}$

Acknowledgments. We thank Dr. Gary Kwong of the $3 \mathrm{M}$ Co. for help in preparing the manuscript. This research was supported by the Korea Research Foundation-C000207 (101794).

\section{References}

1. (a) Tanner, D. D.: Chen, T. J. J. Org. Chem 1989, 54, 3842. (b) Tanner, D. D.: Chen, I. J. J. Ofg. Chem. 1992, 57, 662. (c) Zhu, X.-Q.; Zhang, M.-T.; Yu, A.; Wang, C.-H.; Cheng, J.-P. J. Am. Chem. Soc 2008, 130,2501

2. Lee, 1.-S. H.; Kil, H. J.; Ji, Y. R J. Phis. Org. Chem. 2007, $20,484$.

3. Craig, T. C.; Ekwuribe, N. N.; Fu, C. C.; Walker, K. A. M.
Sinthesis 1981, 303.

4. Lee, I.-S. H.; Jeoung, E. H.; Lee, C. K. I. Hetereocwl. Chent. $1996,33,1711$

5. Pretsch, E.; Clerc, T.; Seibl, I.; Simon, W. Tables of Spectrat Data for Stratcure Determination of Organic Compounds, $2^{\text {th }}$ ed.; 1989 . pp C120-C125.

6. Craik, D. J.; Brownlee, R T. C. Prog Phis. Org. Chem 1983, 14 , 1.

7. Schulman, E. M.; Christensen, K. A.; Grant, D. M.; Walling, C. J. Org. Chen. 1974, 39, 2686.

8. Hamer, G K.; Peat, I. R.; Reynolds, W. F. Con. J. Chem. 1973, 51, 897.

9. (a) Robinson, C. N.; Stablein, G E.; Slater, C. D. Tetrahedron 1990, 46, 335. (b) Pavia, D. L.; Lampman, G. M.; Kriz, G. S. Introdiction to Spectroscopl; $3^{\text {nt }}$ ed.; Harcourt, Inc.: Orlando, FL, 2001; pp A29-A30.

10. Breitmaier, E.; Voelter, W. Carbon-13 NMR Spectroscop!; $3^{\text {nd }}$ ed.; VCH: Weinheim, Gennany, 1987; p 110.

11. (a) Lee, I.-S. H.; Jeoung, E. H.; Kreevoy, M. M. J. Am. Chem. Soc. 1997, 119, 2722. (b) Zhu, X.-Q.; Zhang, M.-T.; Yu, A.; Wang, C.H.; Cheng, J.P. J. An. Chen. Soc. 2008, 130, 2501. 